\title{
NARRATIVAS E TRAJETÓRIAS: abordagens metodológicas a partir da UNILAB
}

\author{
Mario Henrique Castro Benevides* \\ Carlos Henrique Lopes Pinheiro**
}

\begin{abstract}
Tomando a realidade da Universidade da Integração Internacional da Lusofonia Afro-brasileira (UNILAB) como ponto de partida, discutem-se abordagens teórico-metodológicas das ciências sociais e sua revisão no contexto da "lusofonia". Diversas metodologias qualitativas são abordadas e desnudadas, considerando-se o contexto de sujeitos sociais ligados aos países da CPLP e ao mundo colonial. Na busca por uma sociologia das falas e uma geografia dos discursos, damos ênfase à importância do cotidiano como base de trabalho e reflexão epistemológica. Pensá-lo continuamente a partir das diferenças relacionais que o contexto lusófono provoca, é parte do resultado da reflexão do pesquisador nessa seara.

Palavras-chave: Metodologia. Lusofonia. Narrativas. Estudos de trajetória. Educação superior.
\end{abstract}

\section{INTRODUÇÃO}

O presente artigo busca analisar e refletir acerca das abordagens metodológicas e conceituais de pesquisa qualitativa, privilegiando as estratégias e recursos da oralidade, especialmente dos conceitos de narrativa e trajetória. As reflexões em questão nascem a partir do cotidiano e das práticas docentes de professores e professoras da Universidade da Integração Internacional da Lusofonia Afro-Brasileira (UNILAB), ainda que ganhem aqui um caráter mais amplo. O contexto, a proposta e os sujeitos que formam essa universidade, insere docentes, pesquisador ou pesquisadora, em um conjunto de possibilidades e desafios capazes de ressignificar suas práticas de ensino e demais atividades acadêmicas. Desse modo, trata-se de um artigo derivado da observação

\footnotetext{
* Universidade da Integraç̃o Internacional da Lusofonia Afro-Brasileira - UNILAB. Instituto de Humanidades e Letras. Av. da Abolição, 3. Centro. Cep: 62.790-000. Redenção Ceará - Brasil. mario.castro@unilab.edu.br

* * Universidade da Integração Internacional da Lusofonia Afro-Brasileira - UNILAB. Instituto de Humanidades e Letras. Mestrado Interdisciplinar em Humanidades Av. da Abolição, 3. Centro. Cep: 62.790-000. Redenção Ceará - Brasil. carlos.henrique@unilab.edu.br
}

e do planejamento de estudos na realidade da UNILAB, embora a extrapole, de modo a imaginar implicações de método na investigação das ciências humanas. Apresenta, assim, essencialmente, considerações teórico-metodológicas derivadas de uma inserção, visando a contribuir no debate maior sobre o acesso metodológico sobre as oralidades.

O professor, como possível sujeito de estudo, por exemplo, constrói e reconstrói suas trajetórias a partir de suas narrativas e experiências, atribuindo, constantemente, novos significados e sentidos a seu labor. Ao entrelaçar concepção, percepção e vivência, atribui não apenas novos contornos e significados ao trabalho docente, mas revela dimensões representativas e singularidades da realidade estudada não só na perspectiva individual, como na perspectiva coletiva da qual essa individualidade é produto e produtora.

O saber dos professores não é um conjunto de conteúdos cognitivos definidos de uma vez por todas, mas um processo em construção ao longo de sua carreira profissional na qual o professor aprende de maneira progressiva a dominar seu ambiente de trabalho, ao mesmo tempo em que se insere nele e o 
interioriza por meio de regras de ação que se tornam prática integrante de sua consciência prática (Tardif, 2011, p. 14).

Assim, lançamos um olhar sobre a oralidade, atentando tanto para a compreensão quanto para o desenvolvimento de estratégias metodológicas que buscam conhecimento, autoconhecimento e reconhecimento do e no espaço dito lusófono. Partimos, pois, do pressuposto, de que o professor, por exemplo, busca dar respostas e construir questionamentos aos contextos sociais e políticos em que está inserido. Nessa perspectiva, cumpre colocar algumas indagações. Qual o entendimento de lusofonia e como ele permeia as reflexões sobre ensino e pesquisa dos docentes da UNILAB? Como são pensados os percursos e estratégias metodológicas no contexto da interculturalidade? Considerando os relatos orais como fontes primárias de coleta de dados, como podemos refletir e trabalhar, nas pesquisas qualitativas, sobre oralidades, narrativas e trajetórias nos estudos sobre identidade e representação social?

Dessa forma, o trabalho tem como objetivo apontar uma série de reflexões metodológicas a partir de um campo de pesquisa específico, a UNILAB, articulando, a partir daí, um ensaio sobre metodologias de pesquisa qualitativa fundadas em conceitos como narrativa $\infty$ e trajetória. Envolve a descrição de um espaço ง permeado por um fenômeno social bastante relevante: os contatos entre os diferentes países สี่ africanos de língua portuguesa e o Brasil, ex¿ pressos nas narrativas e trajetórias de sujeitos sociais desses países. A motivação é direta: a criação da UNILAB como lugar e eixo de novas * relações da Comunidade dos Países de Língua \& Portuguesa (CPLP). Criada em 2010 e voltada ले para o atendimento de alunos de sete países $>$ da CPLP, a UNILAB tem fomentado debates não apenas no âmbito da educação superior, mas também nas abordagens e estudos sobre alteridade, identidade e expressão. Tomando a experiência docente e discente na UNILAB, mas registrando também os contatos paralelos das políticas de integração e cooperação de- senvolvidas entre esses países na década de 2010, a pesquisa em foco traduz uma urgência de memória: entender os elementos que constituem a feitura das histórias de vida, das observações sobre o mundo e sobre o eu nas várias experiências enfrentadas. Experiências de viagem, de autorreconhecimento, de identificação prática, de conflito e estranhamento, e de fortalecimento das comunidades de sentido que a vida social acessa, reforça, transforma. Assim, o mote e a matéria-prima para tais considerações de método advêm de um conjunto de observações sistemáticas, de experiências e levantamentos realizados ao longo de 2014, no espaço da UNILAB, e que tem contribuído para a criação de um arquivo de opções de trabalho acerca da realidade (e do objeto teórico em construção) representada pelas instâncias de um espaço de encontros e de choques.

É sob essa inspiração e preocupação que articulamos questões de método e de aproximação com a realidade social do vivido, do cotidiano, nos campos em que a "integração internacional" se torna encontro cultural: recorte fundamental para uma pesquisa social sobre diferenças e a produção cultural de unidades políticas.

O conceito de narrativa pode ser captado a partir do ato de registrar eventos, descrever acontecimentos e estabelecer, por meio de aparatos simbólicos, o sentido deles para a formulação de visões morais, de encontros culturais ou de sistemas sociais de experiência (Oliveira; Santos; Susin, 2014). A narrativa representa o elemento oral que alcançamos e com o qual dialogamos na coleta qualitativa em questão neste estudo. Ela se apresenta nas entrevistas, na história dos sujeitos, na compilação criativa que emerge dos diálogos intermitentes a que a integração convida - entremeados no português como idioma do contato. Dessa forma, a UNILAB, em exemplo, é, em si mesma, um conteúdo narrativo trabalhado nas expressões dos sujeitos que aqui transitam e que a incorporam, com frequência, à leitura de seu momento e dos cortes de experimentação que habitar esse espaço traz. 
As espacialidades, linguagens e memórias no âmbito social da lusofonia - mas também das demais realidades de linguagem plural que cercam a UNILAB - constituem uma área de estudos profundamente transversal e integrada, porque emergem no plano de um conjunto de territórios e nacionalidades em constante formação e reformação, tais como o Brasil, Portugal, Moçambique, Timor Leste, Guiné Bissau e demais países de língua portuguesa oficial. Esses elementos vão muito além da língua: subsistem como elementos da cultura e sociabilidade, do território e da identificação política e, por isso, se faz urgente a investigação sobre as relações nesses lugares de experiência histórica interligada no contexto de sua integração presente. É a esse ambiente temático que esta discussão se filia, articulando diferentes áreas do saber acadêmico na elaboração de pesquisas de diferentes fontes, mas transversalmente povoadas pela questão da imaginação identitária e pelo imaginário do trajeto, do reconhecimento territorial e da ruptura multiterritorial que inaugura a integração entre diferentes países. Assim, a pesquisa contínua que será aqui apresentada tem o intuito de movimentar e desenvolver discussões metodológicas sobre a produção de histórias e relatos nos mais variados formatos, dentro dos países de língua portuguesa, pensando os recursos de sua criação, bem como os sujeitos, cotidianamente produtores e produtos das forças de sentido de mais de uma indústria simbólica das identidades em trânsito.

A trajetória, por seu turno, pode ser compreendida como um modo de ver as dimensões biográficas em recorte. No caso da experiência do professor, a dimensão do trabalho docente emerge como elemento de observação, e a trajetória é aqui pensada como elemento de sua memória, significação e definição narrativa. Os estudos de trajetória dentro da UNILAB promovem reflexão sobre a aglutinação de formações do serviço público, assim como servem de testemunho acerca da emergência concreta de uma política de cooperação internacional que surgia no contexto do governo Lula e do Governo Dilma: um sistema de expectativas e relações que falariam sobre um dado tipo de conhecimento geográfico, histórico e antropológico. Grosso modo, o estudo das trajetórias unilabianas, ainda que delimitadas aqui a um tipo claro de agente, o professor, implicam um exame recortado de um fenômeno de encontro. Um encontro motivado por uma agenda político-social e preenchido pela dinamicidade das escolhas de profissionais que aderiram a um projeto universitário demarcado e novo.

O estudo toma, então, a narrativa e a trajetória como conceitos-chave de operação, numa tentativa de superação da ideia de identidades culturais fixas. Desse modo, a pesquisa inclui, como seu objetivo, discutir e integrar um fórum metodológico para a construção de pesquisas no campo da integração Brasil-África, pensando, em longo prazo, na produção de um acervo material e teórico para os estudos da cultura, da política, do trabalho e do território a partir das histórias, biografias, relatos e produções de enredo de sujeitos, grupos e instituições que edificam essa realidade. Pensando o relato oral e também o documento como fontes para pesquisa nas Humanidades, este artigo entende que os sentidos de produção da história e da condição biográfica são bases para a compreensão do humano, sendo a linguagem - e o português, nesse caso - um dos muitos instrumentos para a compreensão de sua complexidade.

\section{A UNILAB COMO CAMPO DE ES- TUDOS POSSÍVEL, SINGULAR E COMPLEXO}

\section{Caminhos de formação}

Criada em 2010 pela Lei $\mathrm{n}^{\mathrm{o}}$ 12.289/2010 e localizada nos municípios de Redenção e Acarape, no Ceará, e São Francisco do Conde, na Bahia, a Universidade da Integração Internacional da Lusofonia Afro-Brasileira 
(UNILAB) é uma instituição pública federal, de ensino superior, que deve ser compreendida como um projeto político e social estratégico de inclusão na perspectiva da cooperação Sul-Sul, capaz de proporcionar, além da profissionalização qualificada necessária ao contexto em que atua e se situa, um intercâmbio de saberes socialmente relevantes, constituindo-se, assim, como elo histórico e cultural entre o Brasil e os demais países de língua oficial portuguesa.

A UNILAB, portanto, está assentada em um duplo paradigma: da interiorização e da internacionalização. Importa destacar, ainda, que essa IES é parte de um projeto de expansão das universidades públicas federais, iniciado no primeiro mandato do governo Lula (2002), e mantém estreita relação com os campos políticos, econômicos, sociais e culturais da realidade brasileira contemporânea.

Não raro, mais do que as atividades de ensino, pesquisa e extensão, próprias do fazer acadêmico das universidades públicas em geral, é possível identificar, no cotidiano acadêmico, as bandeiras de luta de diversos segmentos sociais representantes das chamadas minorias sociais e étnicas, mas que aqui buscam, formam e amparam entidades promotoras e protetoras dos direitos humanos, como o Movimento Negro, o Movimento LGBT, o Movimento Feminista e o $\infty$ Movimento Indígena, dentre outros que, articu亏ิ lados, contribuem para a promoção do desenvolvimento regional, a superação das desigualdades สี่ regionais e a integração e cooperação solidária internacional. Tais ações, participações e movimentos não são exclusivos dessa universidade, mas são inerentes a ela e fazem parte do processo i de democratização do ensino superior almejado pelo Estado brasileiro, especialmente na primeiiे ra quinzena deste século. Assim, a universidade $>$ da lusofonia é, na realidade, uma universidade polifônica, seja pela diversidade da origem e da trajetória do público que a compõe, seja pela diversidade cultural, religiosa, política e social que modela seu corpus. Logo, seu entendimento perpassa pela reflexão dessa gama de sujeitos, personagens, políticas, cooperações e conflitos.
Nessa teia de articulação política e educacional que envolve órgãos de governo dos países parceiros da Comunidade dos Países de Língua Portuguesa (CPLP), a UNILAB apresenta-se como importante ponto de articulação para acordos bilaterais e (ou) multilaterais visando à emancipação de pessoas e de territórios historicamente marginalizados das ações e estratégias políticas governamentais tradicionais. Evidencia-se, desse modo, que a interiorização aqui institucionalmente destacada é referente a um projeto e à necessidade de inclusão social e espacial inerente a todos os países lusófonos e não apenas pelo fato de a UNILAB estar inserida em cidades de pequeno porte, tanto no estado do Ceará quanto no estado da Bahia.

O projeto da UNILAB, com todos os percalços de sua execução e implementação, sustenta-se na prerrogativa de um movimento de globalização contra-hegemônico, decolonial, pautado na ideia de um desenvolvimento endógeno, com a valorização de recursos locais.

No plano teórico, o que verificamos é a possibilidade de produção de um novo discurso, de uma nova metanarrativa, um novo grande relato. Esse novo discurso ganha relevância pelo fato de que, pela primeira vez na história do homem, se pode constatar a existência de uma universalidade empírica. A universalidade deixa de ser apenas uma elaboração abstrata na mente dos filósofos para resultar da experiência ordinária de cada homem. De tal modo, em um mundo datado como o nosso, a explicação do acontecer pode ser feita a partir de categorias de uma história concreta. É isso, também, que permite conhecer as possibilidades existentes e escrever uma nova história. (Santos, 2001, p. 21).

\section{A "lusofonia" como conceito, a cooperação como cenário}

Domingos Simões, político guineense e secretário da Comunidade de Países de Língua Portuguesa entre 2008 e 2012, assim definiu lusofonia:

Numa primeira análise, a "Lusofonia” pode ser associada a palavras como a Francofonia ou a Anglofonia e acarretar consigo uma carga presumivelmente 
pós-colonial. Dentre alguns estudos sobre esta matéria, realça-se o sentido geopolítico do termo que engloba um conjunto de países e de povos cuja língua materna, corrente ou oficial, é o português.

[...] também pode ser interpretada como um sentimento, como uma alma, como um desejo de viver em conjunto, partilhando um passado comum. E, talvez a dimensão mais vasta do termo designa o conjunto dos Estados e organizações que trabalham em conjunto com o objetivo de desenvolver a língua e as sociedades, internamente e por fora.

A Lusofonia na atualidade, creio eu, é um termo que obedece ao princípio da globalização e interdisciplinaridade onde se almeja afirmar uma identidade comunitária, para além da questão linguística. ${ }^{1}$

Esse conceito nos ajuda a entender dois aspectos importantes do quadro lusófono: a vastidão política que abarca e preenche a discussão da língua e a conexão entre os mundos sociais representados por esses países, presente, por exemplo, no anseio pela efetivação de uma comunidade, de uma união até então apenas ensaiada pelo parentesco de idioma e pelo passado. Em contextos de desenvolvimento atrelados à história da colonização e das lutas por independência, os países da CPLP vêm vivendo laços cada vez mais estreitos. O trânsito de estudantes originários dos países africanos no Brasil, por exemplo, registra uma nova rota de formação e de troca de experiências. De um lado, tem configurado um destino de profissionalização adicional para sujeitos sociais cujas expectativas eram, antes, atreladas à Europa, quando o assunto era a formação superior. $\mathrm{O}$ desenvolvimento brasileiro e sua emergência como ator significativo da comunidade econômica do Terceiro Mundo estruturou esse contato e esse plano social novo, administrando toda uma ótica renovada no que diz respeito às possiblidades acadêmicas.

Tais aspectos são suficientes para se compreender a importância dos estudos de narrativa e trajetória. Por meio deles, captamos os vazios e os habitats da cultura pós-colonial, como um mundo cheio de travessias ou tenta-

1 Retirada de http://www.cplp.org/Files/Filer/cplp/Domingos_Simoes_Pereira/Discursos_DSP/SE_TNOVAS 13NOV08.pdf em 26 set. 2014. tivas de travessia. Um mundo cheio de sujeitos com histórias vividas e contadas, em especial aquelas que falam da viagem, da busca, das referências de futuro e de passado na produção de seus trajetos.

No caso da África e de seus muitos territórios modificados pela colonização e pelas reações a ela, temos, na lusofonia, uma estratégia de conexão. Os países africanos lusófonos estabeleceram, nas últimas décadas, um entendimento de comunidade que ainda carrega vazios, mas caminha, aparentemente, para a produção de um mercado simbólico de autoafirmação. É possível dizer, nesse sentido, que o Brasil passou a desempenhar uma imagem de parceria atrativa e em construção. Esse sentimento de elo entre espaços geograficamente distantes pode vir a se espalhar na forma de expectativas políticas de integração. Mas, por enquanto, já se percebem os esforços de aproximação formal - preenchida por formalidades -, o que pode representar um possível primeiro passo na demarcação mais clara de um cenário cultural comum.

Como parte de uma estratégia de produção de protagonismo político brasileiro internacional e inter-regional, a UNILAB aparece como parte de um projeto maior, um instrumento cooperativo proposto pelo segundo Governo Lula e operado na gestão de Dilma Rousseff, direcionado para um desenho inicial de espaços de integração no campo educacional. A aproximação com os governos da CPLP, especialmente no caso dos cinco países lusófonos em África (Moçambique, Angola, Guiné-Bissau, Cabo Verde e São Tomé e Príncipe) emerge como item de um pacote de contatos com países potencialmente parceiros em um modelo político e teórico denominado Sul-Sul. Essa relação assume estruturas e proposições politicamente engajadas no tema do desenvolvimento, costurando experiências no Brasil com demandas sugeridas no continente africano. Segundo a Ministra do Desenvolvimento Social, Tereza Campello. 
Nós temos uma experiência importante no Brasil, conseguimos, nesses 10 anos, reduzir não só a fome, a insegurança alimentar, como tirar milhões e milhões de pessoas da pobreza. E muitos problemas que nós tínhamos no Brasil são parecidos aos encontrados na África. Então, o Bolsa Família, o Programa de Aquisição de Alimentos, o esforço que nós fizemos de formalizar o emprego e aumentar o salário mínimo. Todas são experiências que os países da África podem aproveitar e têm aproveitado.

A cada semana, nós recebíamos duas delegações [de países que queriam conhecer os programas sociais do Brasil] e, em geral, uma delas era da África. Agora, nós mudamos a forma de trabalhar para melhorar a cooperação, porque é uma das determinações da presidenta Dilma, como era do presidente Lula, que a gente faça cooperação Sul-Sul e os países da África têm prioridade ${ }^{2}$.

A chave posta em movimento nas falas e ações do governo brasileiro tem sido, dessa forma, a cooperação como instrumento de aproximação e composição de alianças SulSul. De volta à esfera da educação, é possível perceber que o projeto cooperativo assume um compromisso de troca de experiências e de formação profissional com a inclusão de temas clássicos no contexto do pós-colonialismo, tais como etnicidade, reflexão sobre a cultura e interculturalidade América-África-Ásia, estudos sobre a consolidação de instituições no Sul e superação de desafios impostos pela c conhecida condição de exploração econômica ণ de momentos históricos anteriores. Essa pauta retoma a lusofonia como marca de atribuição สิ histórica: pensar o passado colonial comum e $\stackrel{\circ}{\infty}$ as barreiras para a conquista de um desenvolSimento almejado parece influir para dentro $\stackrel{0}{2}$ do arcabouço de planejamento de uma educa¿ ção "inter-nacional".

$\dot{a} \quad$ Mas de que forma essas proposições e esके ses planejamentos se expressam nos cotidianos lusófonos? E como, sob o prisma das ciências sociais, a metodologia ganha novo sentido uma vez que diante de novo cenário? A seguir, ت examinaremos alguns dos modelos clássicos de

2 Entrevista concedida ao Instituto Lula em 30 de junho de 2013. Disponível em http://www.institutolula.org/africa-e-prioridade-nos-programas-de-cooperacao-do-brasil e acessada em 09 jul.2014. levantamento metodológico à luz da especificidade desse quadro de condições e horizontes.

Não se trata, portanto, e nestes termos, de considerar a lusofonia como realidade plena ou realidade "orgânica" de cenários como a UNILAB: ela vive ainda como "conceito sob rasura" (Hall, 2000), como ferramenta aproximativa que descreve, de modo parcial, uma realidade discursivamente projetada por forças institucionais. Na prática, a lusofonia é apenas um conjunto de expectativas e adaptações em um cenário de línguas plurais - idiomas como o crioulo são substancialmente importantes em Guiné-Bissau, Cabo Verde e São Tomé e Príncipe, por exemplo. Do modo como a vemos, ela é também dispositivo de integração limitada, mas gera, ainda que dessa forma, expedientes de análise necessária. Situada no Brasil, a UNILAB aparece como uma "comunidade documental” em língua portuguesa, que pressiona, direta ou indiretamente, a oralidade em português - elemento paradoxal, mas presente e, portanto, analisável, de sua concretude.

Nos tópicos seguintes, analisaremos os instrumentais clássicos necessários a uma compreensão da narrativa e da trajetória que emergiram a partir de experiências de desenho de pesquisa dentro do cenário da UNILAB. Assim, será uma travessia conceitual acerca de requisitos e também através de expedientes nascidos da imersão em uma realidade que provoca por suas singularidades internacionais como campo sócio-histórico e geográfico.

\section{NARRATIVAS E TRAJETÓRIAS NOS ESPAÇOS LUSÓFONOS}

Ao observar a realidade docente na universidade, a partir de estudos diversos, nos deparamos com a tarefa inicial de pensar as ferramentas de abordagem e coleta. Os estudos de caráter "social", nas ciências humanas e em áreas de interseção como a Geografia, inspiram a criatividade na busca de formas de acesso ao interlocutor-ator: é por meio desses mecanis- 
mos de interação mediada que a pesquisa ganha possibilidade. Pensar, portanto, suas facetas e desdobramentos é um ponto necessário e, por sua vez, abre o horizonte da reflexão aqui posta: quais os caminhos metodológicos para observação das realidades da "lusofonia" unilabiana?

\section{Oralidades e instrumentos de pesquisa}

Os relatos orais ofertam grande variação de proposições para a compreensão do objeto em análise: narrativa biográfica, história oral, história de vida, descrição de trajetórias, dentre outras. Embora similares e complementares, esses enredos não dispõem do mesmo significado. Cada um desses percursos pode conduzir a resultados únicos, particularizados, e é fundamental que saibamos lidar com as diferenças nessa camada.

A principal similitude dessas abordagens é referente à utilização de entrevistas como recurso metodológico. Considerando essa perspectiva, Sennett (2004, p. 55) esclarece e alerta que:

A entrevista detalhada é uma habilidade característica, com frequência frustrante. Ao contrário de um pesquisador de opinião pública fazendo perguntas, este tipo de entrevistador quer sondar as respostas que as pessoas dão. Para tanto, o entrevistador não pode ser friamente impessoal; ele tem de dar algo de si mesmo para merecer uma resposta sincera. Mas a conversa aderna em outra direção; a questão não é conversar como se faz entre amigos. O entrevistador também descobre frequentemente que ele ofendeu o entrevistado, transgredindo uma linha que somente os amigos ou íntimos podem atravessar. A habilidade consiste em calibrar as distâncias sem deixar o entrevistado se sentir um inseto sob o microscópio.

É possível dizer, dessa forma, que a entrevista, como forma de pesquisa social, imprime uma conexão qualitativa profunda no campo das ciências sociais. Ela (em suas diferentes formas) cria o acesso para camadas mais substanciais de informação sobre o vivido, exigindo, nesse sentido, atenção para sua existência como relação intersubjetiva (entre pesquisa- dor e pesquisado). Neste ínterim, destacamos a necessidade de interação entre as partes para o bom desenvolvimento da pesquisa. Tal interação, não só devido à entrevista, mas também pela afinidade de conhecimento com o assunto pesquisado, é, em geral, outra semelhança que entrelaça as abordagens descritas. Esse conteúdo e esse entendimento da forma fazem da entrevista científica um aparato autorreflexivo sobre as possibilidades do conhecimento do Outro. Ela instaura uma relação de diálogo acerca da visão de mundo do entrevistado, o que permite acessar sua compreensão de temas específicos ou de si mesmo.

Nos campos dos estudos de narrativa e da trajetória, a entrevista compõe a necessidade do qualitativo e do contínuo - ela é uma ferramenta por onde as informações podem circular de modo não mecânico, espera-se. Ela é também uma aproximação atrelada à atenção intermitente entre o conteúdo e a forma do que é dito. No contexto da lusofonia, a entrevista repercute como encontro cultural em si: desde a relação estabelecida na linguagem das perguntas - na clareza das expressões, na constante tradução a que se refere Bhabha (1998) ao falar da condição de cosmopolitismo vernacular. Como experimento de socialização, a entrevista é a tentativa de captar um fluxo de confiança entre entrevistador e entrevistado, cruzando os espaços de intimidação e violência simbólica que a relação gera (Bourdieu, 1989). Ainda que a lusofonia estabeleça aqui uma conexão importante para os estudos entre sujeitos de diferentes realidades nacionais, ela pode ser uma armadilha cognitiva, ao recalcar, por exemplo, que o português não é a língua materna da maioria dos habitantes dos países lusófonos. Nesse sentido, a entrevista, como método básico e flexível, precisa adaptar-se ao movimento de linguagem do entrevistado. É uma necessária tomada de posição franca: a de admitir os afastamentos e as diferenças, ao invés de ocultá-los. O entrevistador é, em tese, o responsável fundamental na produção dessa exposição da realidade da relação-pesquisa. 
As narrativas biográficas, ou simplesmente a biografia, constituem outro dispositivo ainda recorrente nos estudos das humanidades e desdobra-se como um dos núcleos de levantamento sobre a trajetória - ainda que a segunda seja uma espécie de corte sobre a primeira. De acordo com Becker (1997), podemos afirmar, em linhas gerais, que os estudos baseados na reconstituição fiel da experiência do sujeito e a interpretação que ele faz do mundo onde vive têm sido a principal contribuição da apreensão biográfica à análise das ciências humanas de uma forma geral. Tradicionalmente entendida como coleta e análise documental, a oralidade é um recurso importante, dadas as nuances da coleta da memória em tempo real: “... depoimentos inclusive sob a égide da memória e relatos orais têm importância fundamental, pois, entre outras coisas, revelam trajetórias que permeiam o fato histórico da imigração" (Seyferth, 2005, p. 32). Essa abordagem privilegia os fatos históricos, as formas de sociabilidade que ocorreram sobre processos históricos e sociais, enriquecendo o conhecimento sobre as organizações pretéritas da sociedade. Para além das perspectivas históricas, as narrativas desse tipo tratam, ainda, de uma investigação do tempo presente, vivido cotidianamente na atualidade, ao interagir com os sujeitos em atividade, considerando a memória recente, falada e vivida, ainda em construção de si, das identidades e representações sociais.

ปิ O meio biográfico é a base da formação intersubjetiva das trajetórias e da ação de narrar o mundo dos indivíduos. Como tal, estabelece ¿ exigências e opções. Entre as exigências está esta notória carência de contexto: a autobiografia dos pesquisados é apenas parte do recurso, i que só se completa no levantamento de outras $\dot{\sim}$ fontes, na relativização do saber de quem fala. iे Essa "desconfiança" metodológica, contudo, não é unanimidade nas ciências sociais. Especialmente em parte da antropologia, a validação da fala do Outro é condição básica de uma interpretação não normativa e comprometida com a descrição da experiência cultural alheia (Geertz, 2003). Ainda assim, o debate sobre a importância de confrontar (na análise, não na coleta) as falas dos pesquisados implica desmistificar a potência do autorrelato, entendendo-o como ação do falante. E, como ação, está sujeita ou caracterizada por escolhas deliberadas (estratégias) ou não deliberadas (representações sociais, na falta de um conceito melhor) do indivíduo. Assim, a "desconfiança” metodológica diante da biografia é um instrumento que nos envolve frente à história e aos processos formativos do grupo. No caso dos espaços lusófonos, ela remete, imediatamente, às condições pós-coloniais e à herança de estruturações e desestruturações do mundo social dos que falam o português. Segunda exigência, portanto: a aceitação e a operação da memória social e da formação nacional dos lugares de fala dos pesquisados como instrumentos de relativização. Encaramos aqui o mesmo ponto: estabelecer conexões entre o dito e o vivido, entre o vivido e o narrado, além de outras perspectivas sobre as condições de seu surgimento como relato. Não se trata de escalonar entre dados "subjetivos" e "objetivos", mas de reconhecer que o biográfico, como paleta social, é diversamente acessado pelos sujeitos e objetivado pelas realidades materiais e políticas onde eles o constroem; é, assim, uma forma de atribuir ao biográfico um estatuto de artefato cultural - experiência que merece análise de conteúdo e de causas.

Uma opção aberta pela coleta e análise das biografias como parte de um estudo de trajetórias e narrativas é a instituição de uma pesquisa sobre a contação. O ato de contar histórias é, em si, um trecho da cultura pouco mapeado pelas ciências sociais lusófonas. É notório que contrabandeamos recursos conceituais da História e das Letras para compreender os caminhos de produção do conto, do relato não técnico. O que de melhor temos, no que toca esse tipo de abordagem, são os estudos biográficos: por meio deles, aprendemos a desvelar os modos de criação e de registro do que as pessoas fazem em seus "cotidianos de significado". A biografia, como objeto, gerou curiosidade suficiente nas sociologias e antropologias do século XX para gerar um corte de análise sobre os es- 
tudos da fala, da forma de contação da própria vida. Essa é a base sobre a qual surge - e se desenvolve - toda uma "superestrutura" metodológica, mais disposta a compreender os regimes de narração que os sujeitos aprimoram em diferentes contextos. A própria condição colonial e as resistências que ela fez nascer e valer são tópicos desse tema. Temos, no estudo do mundo colonial-pós-colonial, uma gama de modelos de histórias pautadas por comoções, críticas, interjeições, retórica, poética e debates. Com o tempo, aprendemos a valorizar o conteúdo e também a estrutura dessas narrativas, por conta não só de sua relevância política, mas também como forma de análise de seu procedimento, de sua consolidação. Na contracorrente, a biografia dos resistentes desses cenários apresenta-nos os moldes dos discursos de poder, de opressão e de conservação que foram impingidos e reiterados no campo das experiências biografadas e biografáveis. A efetividade dessas relações de pesquisa aparece, por assim dizer, na estruturação em andamento de uma narratologia da cultura lusófona.

Nesse ínterim, a narrativa, a descrição e a produção de um entendimento sobre os acontecimentos, por parte dos sujeitos, estabelecem, como desdobramento, a história oral, que é um importante caminho para se compreender uma dada realidade social, considerando as narrativas como dispositivo metodológico. Elas podem representar experiências concretas, valores socioculturais, pensamentos em comum e percepção similar e compartilhada da realidade que se vive, bem como estabelecer, para a pesquisa social, uma valorização das falas como forma de compreensão de processos amplos, tipicamente ausentes ou cheios de lacunas "documentais" (no sentido do documento histórico escrito clássico). De tal forma que a história oralizada é tanto narração sociologicamente relevante como evidência historiográfica em ascensão.

Em um contexto espacial, temporal e científico bem delimitado, onde os atores, as instituições, as políticas e (ou) os fatos sociais partilham das mesmas experiências, mas não ne- cessariamente dos mesmos sentimentos, da mesma percepção, a história oral apresenta-se como ferramenta possível e viável a esses estudos, para se conhecer e, principalmente, se compreender a trajetória dos sujeitos pesquisados.

É válido dizer que os relatos orais, nessa perspectiva, são fontes indispensáveis de estudos, uma vez que visam a apreender diferentes vivências e trajetórias sobre o mesmo contexto social. Demartini (2005) explica a importância dos relatos orais e adverte que se entende por história oral uma abordagem metodológica em que há um envolvimento do pesquisador com o objeto de estudo, procurando desvendá-lo a partir dos relatos orais dos sujeitos envolvidos, em complementaridade com o uso de outras fontes escritas, iconográficas, etc.

A definição dos objetos, bem como a seleção dos sujeitos e dos relatos dos sujeitos, estabelecendo conexões entre as pessoas e as visões com as quais almejamos trabalhar é outro destaque feito pela autora citada acima. Tal qual Sennett (2004, p. 95), ela afirma ainda que:

O relato oral é coletado em um processo de intera-
ção entrevistado/entrevistador em que este se coloca
em posição de escuta atenta, cuidadosa, paciente, de
modo a estabelecer a cumplicidade necessária para
que o entrevistado se coloque em situação de querer
falar. Desse modo, o pesquisador precisa aprender a
escutar (inclusive o relato "oculto”) para poder en-
contrar o momento certo de colocar as questões que
lhe interessa investigar.

A história oral, dessa forma, possibilita apreender uma variedade de representações, visões e estratégias dos indivíduos socialmente inseridos em posições semelhantes, mas que, nem por isso, possuem, necessariamente, percepções similares. Isso posto, os recursos mencionados anteriormente configuram-se como importantes caminhos para a compreensão das trajetórias dos sujeitos. Tais trajetórias, por sua vez, nos auxiliarão a refletir acerca das identidades e representações que, acreditamos, se remodelem na mobilidade, no percurso.

Pensando a partir daí a realidade dos espaços lusófonos, temos, na história oral, uma 
sequência das relações com o biográfico, as quais, dessa vez, são enfatizadas pelas possibilidades de pensar o mundo do entorno, o contexto que gera, ou ao menos orienta, a produção da trajetória individual e cultural. Em Guiné-Bissau, para citar um exemplo, a oralidade constitui uma forma valiosa de transmissão de saberes e de composição do passado. Ela impõe uma abertura para o entendimento dos eventos na medida em que os relatos cristalizaram o sentido das lutas políticas de independência e da (re)construção do novo país segundo os anseios e adjetivos de suas histórias (Mourão, 2009). Aqui, a ampla trajetória nacional aparece nas falas individuais, o que nos dá um mapa fragmentado, mas útil, dos espelhamentos e ressignificações entre o cenário social e o papel do sujeito.

As trajetórias, como esclarece Bertaux (1979), são definidas a partir de uma relação entre a origem, isto é, o lugar na estrutura de classe da família onde a pessoa nasce, e a trajetória posterior. Michel de Certeau (1994), por sua vez, afirma que as trajetórias evocam, no espaço, a unidade de sucessivos pontos percorridos, sendo desenhada pelos agentes sociais em questão. Os trabalhos que daqui decorrerão buscam traçar e compreender os trajetos, os caminhos percorridos e significados pelos sujeitos investigados, $\infty$ procurando perceber como eles representam o N olhar sobre si e sobre os outros. As trajetórias visam a demonstrar as histórias vividas em diferentes contextos, seus significados, as práticas cotidianas e estratégias de sociabilidade e interação com e no local pesquisado.

Com isso, ao se investigar cada personagem (individual ou coletivamente), esperamos encontrar trajetórias comuns, situações semelhantes vivenciadas nos percursos sociais (ou) espaciais, fios que unam os trajetos, as perspectivas e percepções, fomentando, assim, que consideramos por trajetória. Em outras palavras, mesmo considerando as estratégias e os movimentos individuais, a trajetória, aponta Bourdieu (1996), é a objetivação das relações entre os agentes e as forças presentes no campo.
Ainda segundo o mesmo autor, as trajetórias seriam, assim, o resultado construído de um sistema dos traços pertinentes de uma biografia individual ou de um grupo de biografias (Bourdieu, 1989). Uma trajetória configuraria, portanto, a objetivação das relações entre os agentes e as forças presentes no campo. Diferentemente das biografias, essa objetivação resulta em uma trajetória que descreve uma série de posições sucessivamente ocupadas pelos mesmos agentes. Em verdade, consideramos que as trajetórias individuais podem conduzir a uma trajetória coletiva, de grupo.

\section{CONSIDERAÇÕES SOBRE IDENTIDADES EMPÍRICAS E TENSÕES ENTRE SUJEITOS E PROJETO: narrativas e tra- jetórias nas elaborações dos atores}

A reflexão sobre a dinâmica das cidades, das políticas públicas, dos mercados culturais, do desenvolvimento local e regional, da economia e dos serviços, e dos desafios contemporâneos do mercado de trabalho são temas que despertam o interesse pela leitura contínua e sistemática das conjunturas específicas, como reconhecimento de um "aparato de fatores" com grande poder causal sobre tais realidades. Esse reconhecimento nos conduz à necessidade de lançar um olhar investigativo desses acontecimentos que, em determinados lugares e contextos, têm gerado pequenas e grandes revoluções técnicas, científicas, informacionais e urbanas, tornando cada vez mais complexas essas estruturas como também as próprias relações sociais.

Ligadas a essa demanda, as representações sociais sobre cada um desses aspectos da vida cotidiana envolvem um conjunto de variáveis que se relacionam ao conceito de identidade, tais como "reconhecimento social", "resistência”, "alteridade”, “campo simbólico”, "jogo de interesses", "pertencimento" e "ação social”, expressas tanto conceitualmente quanto nos 
relatos dos sujeitos investigados. "As representações sociais são uma forma de conhecimento socialmente elaborado e compartilhado, com um objetivo prático, e que contribui para a construção de uma realidade comum a um conjunto social" (Jodelet, 2002, p. 22).

Quando pensadas à luz do pós-colonialismo e dos contextos de produção teórico-práticos, as representações assumem as camadas do conflito, da adaptação e da resistência (velada ou aberta, a princípios externos ou a heranças internalizadas).

A ideia de respeito desenvolvida por Sennett (2004, p. 67) para a compreensão da formação do caráter, por exemplo, não só complementa como nos oferece uma boa sistematização das categorias conceituais indicadas acima. Para esse autor, a sociologia tem muitos sinônimos para os diferentes aspectos do respeito, que incluem "status", "prestígio", "reconhecimento", "honra” e "dignidade”.

Vivemos sob um leque de possibilidades identitárias que questionam muito das histórias que nos contaram sobre quem poderíamos ser e que se constituem agora como projetos contingenciais sobre quem podemos ser, levando as incertezas, indagações e questionamentos cotidianos. Paralelamente a práticas sociais que defendem políticas de identidades, defrontamo-nos hoje com configurações pós-identitárias, apontando novas formas de sociabilidade, que constituem, em muitos círculos, o grande projeto político contemporâneo (Moita Lopes; Bastos, 2010, p. 7-8).

Inerente às transformações sociais e espaciais conjuradas pelas temporalidades do mundo lusófono, vislumbra-se a possibilidade de uma socialização de amplitude geoterritorial em que a vida contemporânea entrelaça o mundo pessoal e do trabalho, equipada com leituras sobre o passado e o significado do espaço no âmbito do presente. Isso acaba por repercutir em uma nova concepção da relação entre tempo e espaço e na manifestação do fazer acadêmico, intelectual e profissional, em que os deslocamentos socioespaciais pós-coloniais e a vivência de múltiplos territórios mediatizam experiências e fazem convergir trajetórias distintas.

As relações entre os espaços percebidos, concebidos e vividos se recolocam a cada construção histórico-social específica, ou seja, são de natureza dinâmica e, por isso mesmo, devem ser refletidas dentro de uma contextualização temporo-espacial donde os estudos sobre identidade ou de (des)construção identitária, assim como qualquer outro processo social, não se realizam, nem tampouco podem ser compreendidos, independente dos elementos com os quais se relaciona - abstrata - mas, ao contrário, em consonância com a realidade tangível, materializada, proporcionando a relação percebido/vivido uma natureza dialética e historicamente designada (Haesbert, 2011, p. 59).

Contraposições de valores sociais e ideológicos, entre o que é idealizado e o que é realizado, entre o percebido e o vivido, entre a autonomia e a dependência, a satisfação e a insatisfação, a valorização e a desvalorização, dentre outras, constituem princípios de visão comuns que constituíram as categorias de pensamento e percepção da prática social dos sujeitos em questão.

A relevância talvez seja construída pelos valores que os indivíduos desenvolveram ao longo de suas histórias de vida e nos impactos das mudanças que ocorreram, na medida em que eles narram sua lembrança no presente, procurando capturar e interpretar seu passado (Benjamin apud Barbato; Caixeta, 2011, p.107).

Analisar as trajetórias a partir das narrativas requer um cuidado especial, uma vez que estamos lidando com visões parciais, "retratos" de si próprio, carregados de sentimentos ou ressentimentos, realocações e enfrentamentos acerca dos mundos em reconstrução. Nesse ponto, cabe novamente referência ao pesquisador como sujeito pós-colonial e ao tom político da pesquisa nesse universo. O risco do encantamento e de envolvimento, sem dúvida, se constitui como um dos principais desafios do campo. Afinal, conforme assinala Bourdieu (1996, p.42),

Os "sujeitos"' são, de fato, agentes que atuam e sa- 
bem, dotados de um senso prático [...] de um sistema adquirido de preferências, de princípios de visão e de divisão de estruturas cognitivas duradouras (que são essencialmente produto da incorporação de estruturas objetivas) e de esquemas de ação que orientam a percepção da situação e a resposta adequada.

Nesse sentido,

Estamos lidando com um self narrador, que apresenta múltiplas vozes, indicando diferentes valores, crenças, conceitos e lógicas de pensar e se posicionando por meio de uma certa organização do discurso, resultando de uma multiplicidade de encontros sociais que possibilitam a construção de espaços e intersubjetividade (Rommetveit, 1992), mesmo que pareçam ser unidirecionais (Barbato; Caixeta, 2011, p. 104-105).

As relações entre os sujeitos pesquisados e os contextos culturais, profissionais e espaciais em que estão inseridos se desenvolvem tanto temporalmente (construção das trajetórias), quanto espacialmente (deslocamentos, mobilidade ou migração), considerando as interações pessoais e profissionais constituídas historicamente, relacionadas à perspectiva política, social e cultural.

Inúmeras questões podem ser pontuadas para aprofundamento, tais como: 1) a relação de trabalho e da perspectiva do trabalho nos espaços lusófonos como elo fundamental na produção de identidades coletivas, sem esquecer a inter-relação com a questão ter-

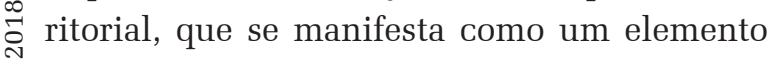
(ت. diferenciador na produção de significados; 2) a identidade nacional e grupal de sujeitos in- fonia em outro ambiente (como o Brasil), pensando-os como referência, pois proporcionam convivências necessárias à construção coletiva de significados, o que solidifica sua identificação como grupo; 5) as profissões imaginadas e esperadas para o futuro, definidas por suas práticas, regras e conhecimentos da atividade que realizam; 6) o espaço como característica central e política (objeto de lutas) das organizações sociais e do ser social, em que os sujeitos se definem, como diz Andy Hargreaves (2004), sendo parte da construção das identidades de resistência e das identidades refeitas, sem referência direta ao mundo colonial, e parte de uma nova memória também buscada; e 7) objetivos institucionais e lógicas públicas entrelaçadas ao discurso sobre e contra o colonialismo, como um dos elementos que unem e contribuem na constituição de identificações e pautas numa dada instituição, como a UNILAB (Franco; Gentil, 2007, p. 52).

Assim, o estudo das trajetórias lusófonas a partir das narrativas possibilita estabelecer uma "teia de significados" que se entrecruzam, formando uma rede de percepções e representações, buscando reconhecer a importância e a riqueza das experiências individuais e coletivas relatadas pelos sujeitos e inscritas conceitualmente, para pôr em evidência generalizações apriorísticas tão tentadoras nessa temática teórico-prática e política.

Marre (apud Gonçalves; Lisboa 2007, p. 87) aponta que “... quando o indivíduo vivencia e relata sua trajetória, se identifica a um grupo social do qual ele é elemento constitutivo". Nesse aspecto, ressalta o autor, a compreensão de um dado fenômeno que utiliza relatos orais para o estudo das trajetórias não consegue chegar ao geral através de uma totalidade de histórias de vida singulares sem dar a elas uma totalidade sintética. Essa totalidade, por sua vez, se forma a partir da singularidade de cada uma delas, cabendo ao pesquisador perceber e refletir sobre a presença das relações básicas e complexas que dizem respeito às categorias sociais expressas nas relações orais. 
Desse modo, nossos interlocutores são concebidos como sujeitos dotados de valores, visões e experiências específicas, cada qual com motivações e trajetórias próprias, mas se encontram em dados momentos no que tange ao elemento socioespacial da construção e da prática profissional. É preciso considerar, nesse caso, a tensão entre a objetividade do alcance da profissão desejada e a subjetividade das sensações pessoais e das relações sociais advindas desde então.

O trabalho com trajetórias revela, para nós, alguns pontos que merecem destaque. Inicialmente, podemos compreendê-lo como uma modalidade de pesquisa que utiliza diferentes técnicas de entrevista para captar a fala dos indivíduos de um determinado grupo ou classe a fim de perfazer um construto histórico e social, lançando um olhar crítico e analítico sobre um dado processo ou fenômeno. Ademais, na perspectiva das humanidades, essa abordagem exige mais que um estudo puramente biográfico, que considera o indivíduo de forma isolada, exaltando sua história de vida, narrada de forma sistemática e parcial, geralmente com um viés de superação ou heroísmo. Trata-se, sim, de uma proposta de investigação que implica compreender universos sociais contextualizados e interconectados à luz da realidade das trajetórias de vida narradas pelos sujeitos pesquisados (Gonçalves; Lisboa, 2007). Combinando essa percepção com as historicidades e espacialidades das biografias lusófonas - essecialmente vívidas no ângulo da colonização e das resistências a ela - temos a chance de observar a formação das biografias a partir das referências e exclusões sobre o mundo formado pelo mercantilismo. É uma forma imediata de tratar a pesquisa social como diálogo junto a mundos políticos expressos no dia a dia, mas validado em histórias coletivas mais amplas.

Dubar (1998) busca elencar alguns aspectos que estabelecem as relações existentes entre as trajetórias sociais e as formas identitárias. Para esse autor, a análise das trajetórias sociais defronta-se com uma inevitável articulação en- tre os aspectos objetivos e subjetivos. A trajetória objetiva é definida como sequência das posições sociais durante a vida do sujeito. A trajetória subjetiva, por sua vez, é expressa nos relatos desses sujeitos e remete à construção dos "mundos sociais", à luz de quem narra essa construção.

\begin{abstract}
As identidades sociais e profissionais típicas não são nem expressões psicológicas de personalidades individuais nem produtos de estruturas ou de políticas econômicas que se impõem do alto, são construções sociais que implicam a interação entre as trajetórias e os sistemas de emprego, de trabalho e de formação (Dubar, 1995, p. 262).
\end{abstract}

Assim, a prática social se entrecruza com a história pessoal, e o relato dessa confrontação possibilita a atualização das visões que o sujeito possui de si e do mundo, interferindo na própria noção de identidade.

Nessa perspectiva, a trajetória diz respeito aos vários espaços ou campos sociais (campos de força, de relações e de lutas) de que o indivíduo fez parte e que o ajudaram a se posicionar em relação aos lugares que ocupa hoje nos campos sociais de que faz parte. A ideia de trajetória representa um processo que fala (e se preocupa, como conceito) com as disposições, ou seja, com os modos e propensões de ser e agir, conforme destaca Bourdieu (2008). Procuramos, com isso, observar o modo como os sujeitos operam suas vidas e não apenas as condições adversas que produzem suas situações e representações, embora tais condições não possam ser desprezadas.

Assim, as trajetórias assumem um caráter disposicional e não conjuntural, sendo, portanto, construções coletivas, sociais. Suas práticas, por mais singulares que possam ser e se apresentar, estão marcadas pelo destino coletivo. Buscamos priorizar, desse modo, as impressões dos interlocutores mediante suas próprias leituras das condições e contextos em que estão inseridos. Tais condições estão relacionadas a uma leitura particularizada do real, e não ao real objetivado estatística e politicamente, de modo oficial. 
Lahire (2004, p. 27) destaca que o caráter disposicional da sociologia e das trajetórias está fundamentalmente ligado, em sentido amplo, a uma sociologia da educação, isto é, a uma sociologia da socialização. Para ele,

[...] uma disposição é uma realidade reconstruída que, como tal, nunca é observada diretamente. Portanto, falar de disposição pressupõe a realização de um trabalho interpretativo para dar conta de comportamentos, práticas, opiniões, etc. Trata-se de fazer aparecer o ou os princípios que geraram a aparente diversidade das práticas. Ao mesmo tempo, essas práticas são constituídas como tantos outros indicadores da disposição.

Interessa-nos discutir as relações entre as atividades pessoais e as interações com os demais sujeitos e espaços percorridos e vividos, procurando descobrir a forma como elas se tornam visíveis, racionais e reportáveis, ou seja, um modo de torná-las válidas, social e sociologicamente relevantes, uma vez que a reflexão e os reflexos do eu sobre o fenômeno investigado constituem uma característica singular da ação.

[...] as atividades ordinárias dos indivíduos consistem de métodos para tornar analisáveis as ações práticas, as circunstâncias, o conhecimento baseado no senso comum sobre as estruturas sociais e o raciocínio sociológico prático, assim como de entender suas propriedades formais vistas "de dentro" dos ambientes como parte integrante do próprio ambiente (Haguette, 2005 p. 50).

A tentativa de interpretação das semelhanças e diferenças do conjunto dessas realidades narradas projeta a trajetória como um modelo de análise, uma proposta investigativa que implica um processo de compreensão das falas e das relações socioespaciais, possibilitando uma leitura social de múltiplas vertentes e construtos, inicialmente de forma individual e, em seguida, categorizando e analisando sob a perspectiva da totalidade, sobre uma realidade viva, iminente, histórica e coletiva. تే (Gonçalves; Lisboa, 2007).

Os "sujeitos" são, de fato, agentes que atuam e que sabem, dotados de um senso prático, de um sistema adquirido de preferências, de princípios de visão e divisão (o que comumente chamamos de gosto), de estruturas cognitivas duradouras (que são essencialmente produto da incorporação de estruturas objetivas) e de esquemas de ação que orientam a percepção da situação e da resposta adequada. O habitus é essa espécie de senso prático do que deve se fazer em dada situação - o que chamamos, no esporte, o senso do jogo, arte de antecipar o futuro do jogo inscrito, em esboço, no estado atual do jogo (Bourdieu, 1996, p. 42).

Cada abordagem sugere novas variáveis, novas questões, mais em decorrência da ratificação das abordagens anteriores do que necessariamente de posicionamentos, olhares e percepções completamente inéditos. Nessa perspectiva, objetiva-se apreender diferentes vivências e trajetórias sobre os contextos investigados, com o intuito de compreender suas táticas, suas suposições, seu mundo e os constrangimentos e as pressões aos quais estão sujeitos.

As referências que fazemos ao campo remetem sempre a uma tentativa de diálogo com as definições tradicionais da metodologia, e não de afirmação. Diálogo porque o "mecanismo" que utilizamos não nega a existência e a importância desses instrumentos de pesquisa para a prática intelectual, mas, ao contrário, além de colaborar, eles reforçam a premissa orgânica de descrever o esforço metodológico sem promessas de adesão plena. Afinal, articulamos, no decorrer das pesquisas, cada uma dessas experiências, fazendo uso de sua polissemia e pensando o pesquisado no calor da investigação cotidiana. Dito isso, a determinação de nossas ferramentas metodológicas é sempre uma aproximação imprecisa, que é mais dependente da concordância do interlocutor científico do que de qualquer objetividade inflexível.

Assim, visamos a compreender nossos interlocutores em seus espaços de ação social, política e acadêmica. A nossa proposta metodológica, portanto, intenta estudar os sujeitos em processo, durante o desenrolar de suas trajetórias, observando seus comportamentos e estratégias de sociabilidade e territorialidade, tentando compreender os campos objetivos e 
subjetivos da prática e da vivência docente em condições e conjunturas específicas.

\section{PROPOSIÇÕES FINAIS}

O campo diversamente povoado de narrativas e trajetórias da lusofonia responde a uma necessidade de pontuar a dimensão política da cultura: o cultural, tipicamente associado ao cotidiano folclórico, é emblemático das necessidades, demandas e estratégias dos grupos sociais lusófonos, ainda mais levando em conta o histórico de lutas e resistências que a maioria dos países em questão tem enfrentado ao longo dos séculos. É possível ainda dizer que as metáforas culturais presentes na língua, na linguagem e na comunicação, em sua forma geral, instituem formas de identificação coletiva e formas de composição do futuro com base em imagens sociais do passado e do presente. Daí a urgência de observação e registro desses aspectos autobiográficos e de história escrita ou falada acerca das experiências de pessoas e instituições nesses cenários.

Centrado na coleta, no registro e na análise de trajetórias e de contações de histórias lusófonas, a presente base metodológica ressalta a preocupação com o desenvolvimento dos métodos nas ciências sociais e humanas. Por um lado, como forma de acesso mais claro e confiável ao universo do Outro, do pesquisado. Por outro lado, como estímulo para o aprimoramento dos pesquisadores e da pesquisa no âmbito das narrativas.

Quatro desafios estão presentes nessa senda: a capacidade de compreender os diferentes modos de apropriação da lusofonia e dos espaços culturais e territoriais de sua elaboração e difusão; o refinamento da habilidade de coleta e arquivamento de narrativas e histórias de vida e trajeto, tomando a categorização como exercício fundamental e dialógico; a demarcação de objetos claros e intersubjetivamente ricos, expressões da pluralidade das visões de mundo e da pesquisa; e, por fim, a criação de um fórum permanente de produção metodológica nas ciências humanas, pensado a partir de experiências de pesquisadores e pesquisados, em uma constante atualização do arcabouço reflexivo disponível.

"Compreender os diferentes modos de apropriação da lusofonia” é tratar dos lugares de encontro e de significação dos grupos sociais de língua portuguesa. Sua estruturação e o modo pelo qual estabelecem contatos e criam histórias são indissociáveis da língua e de suas opções de expressão e leitura da realidade. Aqui, é necessário tanto uma sociologia das falas como uma geografia dos discursos - modelos de estudos da comunicação como deslocamento dos sujeitos dentro de sua cultura e dos poderes que ela exige ou impóe. Se, por um lado, a sociologia remete às conexões intermitentes entre o dito e o imaginado nas relações político-sociais, é a geografia que nos atesta, metodologicamente, as atenções sobre o espaço historicamente produzido que vive no discurso de produção do mundo dos sujeitos. Em resumo: a afinidade metodológica proposta obriga-nos a ir além do reconhecimento das espacialidades e de suas influências; incorpora, antes de tudo, um compromisso com os mapas políticos introjetados pelos pesquisados a partir de suas autorreconstituições biográficas.

Por sua vez, "a habilidade de coleta e arquivamento das narrativas e histórias de vida e trajeto" envolve desde listas de metodologias, como as aqui mencionadas e pontuadas, até um compromisso prático na criação de formas de separação e salvaguarda das informações como bancos de dados, ficheiros e espaço físico que comporte um acervo de narrativas e documentos. Um instrumental que possa ser usado e revisto, reutilizado e repensado, inclusive por outros pesquisadores no futuro. Esse elemento insiste no pressuposto de uma visão de si, como atividade científica e social: uma pesquisa que lide com a memória das experiências de vida e travessia não pode ignorar-se como experiência de memorização institucional.

Tomando, portanto, a riqueza das possi- 
bilidades de coleta, já que os sujeitos sociais demonstram diversidade de interlocução e diversidade na condução de suas trajetórias, o ponto de "demarcação de objetos claros e intersubjetivamente ricos" envolve uma disponibilidade para a experimentação de métodos. Indo desde a clássica entrevista semiestruturada, mas passando pela entrevista com recursos visuais e pela etnografia de arquivos escritos, o projeto em questão entende-se como momento de trocas de estratégia na busca por atender a diferentes modelos de expressão dos pesquisados. É a partir daí que o último desafio, “criação de um fórum permanente de produção metodológica nas ciências humanas", aparece como estímulo para o desenvolvimento de redes de trabalho e discussão com cientistas profissionais, mas também com sujeitos nos mais variados estatutos epistemológicos: os estudos de trajetória e narrativa só podem ser considerados como efetivos na medida em que acessam as formas pelas quais as vivências são vividas e interpretadas pelos que as vivem. A busca por essa completude conceitual move a base desta tentativa de levantamento e estudo. Sem ela, o entendimento histórico-social do objeto à nossa frente ficaria enfraquecido pelo mecanicismo e pelo eruditismo ingênuos.

É para cada um desses momentos de $\infty$ percepção sobre a prática heurística que o స్ trabalho em questão se volta, para o cotidiano como categoria final. Entendemos que o สี cotidiano - a rotina simples, o dia a dia não ¿ categorizado, a experiência do imediato - abre $\vec{\delta}$ portas para pesquisas sobre o passado, a memória, o futuro e o projeto como coisas que 今 são constantemente operadas, mesmo que não $\dot{\sim}$ discursivamente, pelos atores do palco social. के E assim, recortando essas minúcias e as obser$\vec{*}$ vações individuais dos sujeitos sobre elas, talvez sejamos capazes de alguma profundidade sobre as ações humanas nas grandes estruturas imaginadas e objetivadas pelo mesmo cotidiano: o planejamento, a viagem, as pressões, os sucessos e os fracassos nascidos nas escolhas limitadas pelo tempo e pelas conjunturas sub- jetivamente experimentadas. Aí, nesse ponto, teremos cruzado coletivamente as interpretações sobre identidade, trajetória e produção de enredos reais da cultura.

Recebido para publicação em 20 de agosto de 2015 Aceito em 30 de novembro de 2017

\section{REFERÊNCIAS}

BARBATO, Silviane; CAIXETA, Juliana Eugênia In: MOITA LOPES, Luis Paulo da; BASTOS, Luis Cabral. Estudos de identidade: entre saberes e práticas. Rio de Janeiro: Garamond, 2011.

BERTAUX, Daniel. Destinos sociais e estruturas de classe: para uma crítica da antropologia política. Rio de Janeiro: Zahar, 1979.

BECKER, Olga Maria Schild. Mobilidade espacial da população: conceitos, tipologias, contextos. In: CASTRO, Ina Elias de; CORREAA, Roberto Lobato. Explorações geográficas: percursos no fim do século. Rio de Janeiro: Bertrand Brasil, 1997.

BHABHA, Homi. O local da cultura. Belo Horizonte: Editora UFMG, 1998.

BOURDIEU, Pierre. A distinção: crítica social do julgamento. Porto Alegre: Zouk, 2008.

. O poder simbólico. Lisboa: Difel, 1989.

Razões práticas: sobre a teoria da ação. São Paulo: Papirus, 1996.

CERTEAU, Michel de. A invenção do cotidiano: 1 , artes de fazer. Petrópolis: Vozes, 1994.

DEMARTINI, Zella. "Pesquisa histórico-sociológica, relatos orais e imigração". In: DEMARTINI, Zeila de Brito Fabri; TRUZZI, Oswaldo M. Serra (Orgs.) Estudos migratórios: perspectivas metodológicas. São Carlos: EduFSCar, 2005.

DUBAR, Claude. "Trajetórias sociais e formas identitárias: alguns esclarecimentos conceituais e metodológicos". Educ. Soc. [online], [S.l], v.19, n. 62, p. 13-30, 1998.

Socialização: construção das identidades sociais e profissionais. Porto: Porto Editora, 1995.

FRANCO, Maria Estela Dal Pai; GENTIL, Heloisa Salles. Identidade do professor de ensino superior: questões no entrecruzar de caminhos. In: FRANCO, Maria Estela Dal Pai; KRAHE, Elizabeth D. (Orgs.) Pedagogia universitária e áreas de conhecimento. Porto Alegre: Série RIES/PRONEX EdiPucrs, 2007. V.1.

GEERTZ, Clifford. O saber local. Petrópolis: Editora Vozes, 2003.

GONÇALVES, Rita de Cássia; LISBOA, Teresa Kleba. Sobre o método da história oral em sua modalidade trajetórias de vida. Rev. Kátal, Florianópolis, v. 10, n. especial, p. 83- 92, 2007.

HAESBERT, Rogério. El mito de la desterritorialización: del "fin de los territorios" a la multiterritorialidad. México: Siglo Veintiuno Editores, 2011.

HARGREAVES, Andy. $O$ ensino na sociedade do conhecimento: a educação na era da insegurança. Porto Alegre (RS): Artmed Editora, 2004.

HAGUETTE, Teresa. Metodologias qualitativas na sociologia. Petropólis: Vozes, 2005. 
HALL, Stuart. "Quem precisa de identidade?”. In: Identidade e diferença: a perspectiva dos estudos culturais. Petrópolis: Vozes, 2000.

JODELET, Denise. Representações sociais. Rio de Janeiro: EDUERJ, 2002.

LAHIRE, Bernard. Retratos sociológicos: disposição e variações individuais. São Paulo: Artmed Editora, 2004

MOITA LOPES, Luiz Paulo da; BASTOS Liliana Cabral. Para além da identidade. Fluxos, movimentos e trânsitos. Belo Horizonte: Editora. UFMG, 2010.

MONTAGNER, Miguel Ângelo. "Trajetórias e biografias: notas para uma análise bourdieuziana”. Sociologias, Porto Alegre, v. 9, n. 17, p. 240-264, 2007.

MOURÃO, Danielle Ellery. Identidades em trânsito: África 'na Pasajen': identidades e nacionalidades Guineenses e Cabo-verdianas. Campinas: Arte Escrita, 2009.

NIEWIADOMSKI, Christophe. Sociologia clínica e acontecimentos biográficos. In: PASSEGGI, Maria da Conceição (Org.) Tendências da pesquisa (auto)biográfica. Natal; São Paulo: Paulus, 2008.
OLIVEIRA, Patricia; SANTOS, Hermílio; SUSIN, Priscila. "Narrativas e pesquisa biográfica na sociologia brasileira revisão e perspectivas". Civitas, Porto Alegre, v. 14, n. 2, p. 359-382, maio-ago. 2014.ROMMETVEIT, Ragnar. "Outlines of a dialogically based social-cognitive approach to human cognition and communication". In: WOLD, Astri Heen (Ed.) The dialogical alternative. Oslo: Scandinavian University Press, 1992. p. 19-43.

SANTOS, Milton. Por uma outra globalização: do pensamento único à consciência universal. Rio de Janeiro/ São Paulo: editora Record, 2001.

SENNETT, RICHARD. Respeito: A formação de caráter em um mundo desigual. Rio de Janeiro: Record, 2004.

SEYFERTH, Giralda. "Cartas e narrativas biográficas no estudo da imigração". In: DEMARTINI, Zélia de Brito Fabri; TRUZZI, Oswaldo Mário (Org.) Estudos migratórios: perspectivas metodológicas. São Carlos: Ed. UFSCar, 2005. v. 2. p. 13-52.

TARDIF, Maurice. LESSARD, Claude. O trabalho docente elementos para uma teoria da docência como profissão de interações humanas. 6. ed. Rio de Janeiro: Vozes, 2011. 


\section{NARRATIVES AND TRAJECTORIES: methodological approaches from UNILAB}

\author{
Mario Henrique Castro Benevides \\ Carlos Henrique Lopes Pinheiro
}

Taking the reality of the Universidade $d a$ Integração Internacional da Lusofonia Afrobrasileira (UNILAB) as a starting point, theoreticalmethodological approaches of the social sciences and their revision in the context of "lusophony" are discussed. Several qualitative methodologies are addressed and detailed, considering the context of social subjects linked to the CPLP countries and the colonial world. In the search for a sociology of speech and a geography of discourses, we emphasize the importance of daily life as a basis for work and epistemological reflection. To think of it continually from the relational differences that the lusophone context causes, is part of the result of the researcher's considerations in this field.

Keywords: Methodology. Lusophony. Narratives. Trajectory studies. Higher education.

\section{NARRATIVES ET TRAJECTOIRES: approches méthodologiques sur la base de l'UNILAB}

\author{
Mario Henrique Castro Benevides \\ Carlos Henrique Lopes Pinheiro
}

En prenant comme point de départ la réalité de l'Université pour l'Intégration Internationale de la Lusophonie Afro-brésilienne (UNILAB), nous analysons les approches théoriques et méthodologiques des sciences sociales et nous la reconsidérons dans le cadre de la « lusophonie ». Plusieurs méthodologies qualitatives sont abordées et mises à nu dans le contexte des sujets sociaux liés aux pays de la CPLP et au monde colonial. À la recherche d'une sociologie de la parole et d'une géographie des discours, nous insistons sur l'importance de la vie quotidienne prise comme base de travail et de réflexion épistémologique. $\mathrm{Y}$ penser constamment sans perdre de vue les différences relationnelles provoquées par le contexte lusophone, fait partie du résultat de la réflexion du chercheur dans ce champ.

Mots-clés: Méthodologie. Lusophonie. Récits. Études de trajectoire. Enseignement supérieur.

Mário Henrique Castro Benevides - Doutor em Sociologia. Professor Universidade da Integração Internacional da Lusofonia Afro-Brasileira - UNILAB. Instituto de Humanidades e Letras. Curso de Licenciatura em Sociologia. Lidera o Grupo de Pesquisa em Narrativa, Política e Pensamento Social no Sul Global, desenvolvendo pesquisas na área de Ciências Sociais, com ênfase em Teoria Social, Sociologia Política e Sociologia dos Imaginários e da Cultura. Suas mais recentes publicações são: Os meios de produção da definição: desenvolvimento, regionalização e poder na ação discursiva do estado no Brasil. Lua Nova. Revista de Cultura e Política, p. 221-257, 2017; Condições de trabalho na educação superior e organização docente na perspectiva recente das políticas educacionais brasileiras. O Público e o Privado (UECE), v. 25, p. 43-54, 2015.

Carlos Henrique Lopes Pinheiro - Doutor em Sociologia. Pós-doutorado em Educação: conhecimento e inclusão social. Professor do Instituto de Humanidades e Letras e do Mestrado Interdisciplinar em Humanidades. Lidera o Núcleo de Estudos Interdisciplinares em Educação, Cidades e Territórios, desenvolvendo pesquisas nas áreas de Educação Superior; Trabalho Docente; Cidades, Territórios e Políticas Públicas. Suas mais recentes publicações são: O processo de des(re)territorialização na comunidade do Tomé, Chapada do Apodi-CE. In: Antonio Vieira da Silva Filho; Jeannette Filomento Pouchain Ramos; Roberto Kennedy Gomes Franco. (Org.). Ensaios Interdisciplinares em Humanidades. 1ed.Fortaleza: Editora da Universidade Estadual do Ceará, 2017, v. 1, p. 114-134; A interdisciplinaridade no ensino médio: apontamentos iniciais sobre reflexões e experiências docentes no Maciço do Baturité-CE. In: Antonio Vieira da Silva Filho; Jeannette Filomento Pouchain Ramos; Roberto Kennedy Gomes Franco. (Org.). Ensaios Interdisciplinares em Humanidades. 1ed. Fortaleza: Editora da Universidade Estadual do Ceará, 2017, v. 1, p. 135-154; Condições de trabalho na educação superior e organização docente na perspectiva recente das políticas educacionais brasileiras. O público e o privado, v. 01, p. 43-54, 2015. 